Eixo Roda, Belo Horizonte, v. 28, n. 3, p. 281-289, 2019

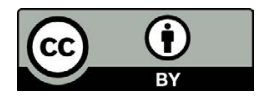

\title{
BRECHT, Bertolt. Se os tubarões fossem homens. Tradução de Cristiane Röhrig. Ilustrações de Nelson Cruz. Curitiba: Edições Olho de Vidro, 2018.
}

Fabiano Tadeu Grazioli

Universidade Regional do Alto Uruguai e das Missões (URI) - Campus de Erechim, Erechim, Rio Grande do Sul / Brasil

Faculdade Anglicana de Erechim (FAE), Erechim, Rio Grande do Sul / Brasil tadeugraz@yahoo.com.br

Se os tubarões fossem homens, de Bertolt Brecht, tradução de Cristiane Röhrig, publicação das Edições Olho de Vidro, surgiu no cenário da literatura infantil brasileira no apagar das luzes do ano passado. Tratase de uma das narrativas que compõem, originalmente, o livro Histórias do Sr. Keuner, publicado no Brasil pela Editora 34, em 2006, dois anos depois de ser publicado na Alemanha. A princípio, as histórias desse livro, que formam escritas de 1926 a 1956, ano da morte do autor, não são endereçadas às crianças, mas como na literatura infantil o melhor é não se pautar por esquemas rígidos de classificação e categorização de textos que não privilegiem a abertura para a inteligência e o despertar do senso crítico do leitor, o trabalho sensível dos editores pôde apontar, entre os textos de Brecht, um que poderia estabelecer um diálogo profícuo com as crianças brasileiras, e, assim, Se os tubarões fossem homens surgiu no formato de livro ilustrado, com parceria de Nelson Cruz, reconhecido não só por suas premiações - recebeu o Jabuti 2018 de ilustração para $O s$ trabalhos da mão, de Alfredo Bosi (Positivo), só para citar a última-, mas principalmente pela proposta criativa e provocadora das suas criações.

O processo narrativo na obra em questão estabelece-se a partir da pergunta de uma criança, a filha pequena da dona da hospedaria, ao senhor K. (ou senhor Keuner, considerado por muitos uma espécie de alter ego de Brecht). Indaga ela: "Se os tubarões fossem homens, será 
que eles seriam mais gentis com os peixinhos?" (BRECHT, 2018). Essa pergunta desencadeia um conjunto de respostas positivas, porém irônicas, que aludem a temas como liberdade, sobrevivência, educação, crenças políticas, guerra e paz, poder e o uso que se faz dele, entre outros. "Se os tubarões fossem homens, mandariam construir para os peixinhos enormes gaiolas no mar, que seriam abastecidas com toda a sorte de alimentos, tanto vegetais como animais" (BRECHT, 2018). Já na primeira resposta do senhor $\mathrm{K}$. à menina, nota-se que a liberdade dos peixes estaria ameaçada, pois, ao invés de eles poderem explorar a imensidão do oceano, eles viveriam aprisionados, embora fossem receber alimento, uma troca que, para os tubarões, parece justa. Nota-se a sutil ironia do interlocutor da menina, nessa e em outras respostas, por meio das quais Brecht constrói uma reflexão corrosiva sobre a sociedade da sua época. Muitos são os aspectos que merecem ser evidenciados e aprofundados em um trabalho mais extenso, mas, tendo em vista o espaço de que dispomos, privilegiaremos, nesta resenha, a ironia enquanto recurso de que Brecht lança mão para compor seu texto e, ainda, o projeto ilustrativo de Nelson Cruz.

A utilização da ironia pelo autor alemão em Se os tubarões fossem homens é um recurso que nos permite algumas reflexões importantes sobre a construção do texto. Lélia Parreira Duarte (2006, p. 19) afirma que

[...] nada pode ser considerado irônico se não for proposto e visto como tal; não há ironia sem ironista, e este será alguém que percebe dualidades ou múltiplas possibilidades de sentido e as explora em enunciados irônicos, cujo propósito somente se completa no efeito correspondente, isto é, numa recepção que perceba a duplicidade de sentido e a inversão ou a diferença existente entre a mensagem enviada e pretendida.

O texto de Brecht para a obra em questão é, na maioria de seus enunciados, uma proposta irônica de seu criador, ou seja, o autor procede com uma série de afirmações, mas espera que, na leitura, seus interlocutores entendam-nas pelo sentido contrário, fazendo-se valer da ironia para revelar o sentido que realmente procura construir, como no exemplo: 
Naturalmente também haveria escolas dentro das grandes gaiolas. Nessas escolas os peixinhos aprenderiam como nadar para dentro da boca dos tubarões. Deveriam ter noção de geografia para poder localizar melhor os tubarões grandes que ficam nadando por aí, preguiçosos. (BRECHT, 2018).

Obviamente, perceberão a filha da dona da hospedaria e a criança leitora que a escola precisa instruir os peixinhos para que eles não sejam presas dos tubarões e salvem suas vidas. Mas, valendo-se da ironia, Brecht afirma exatamente o contrário, para que a interlocutora do senhor $\mathrm{K}$. e o leitor joguem com o texto e estabeleçam o sentido pretendido pelo "ironista", para usar a nomenclatura de Duarte. Ainda a fim de exemplificar a ironia no texto, citamos:

Os teatros do fundo do mar mostrariam valentes peixinhos, nadando entusiasmados em direção à boca dos tubarões. $\mathrm{E}$ a música seria tão bonita que os peixinhos, embalados por seus acordes, seguiriam a orquestra inebriados e envolvidos em pensamentos agradáveis e se precipitariam na boca dos tubarões. (BRECHT, 2018).

A função da arte é colocada em evidência na construção irônica desse parágrafo da obra. Naturalmente, o teatro e a música possuem a função de instruir, assim como a escola, para a emancipação e a independência dos laços de dominação do indivíduo. A obra dramatúrgica e poética que Brecht legou-nos é, inclusive, um investimento nessa perspectiva. Contudo, as palavras do senhor K., ditas à filha pequena da dona da hospedaria informam exatamente o contrário. É preciso que ela, assim como toda criança que vier a entrar em contato com a obra, perceba a diferença entre mensagem "enviada" e mensagem "pretendida". Para arrematar nossa breve exemplificação acerca da ironia na construção dos enunciados da obra resenhada, trouxemos ao texto uma breve, porém potencial, construção de Brecht. Na voz do senhor K., afirma ele: "Haveria também uma religião se os tubarões fossem homens. Ela ensinaria que a verdadeira vida dos peixinhos só começa na barriga dos tubarões" (BRECHT, 2018). A criança, por mais que não reflita sobre crenças religiosas costumeiramente, vê-se provocada pela ironia desse fragmento. Sabe ela que precisa entender o contrário, ou seja, que a vida inicia ao nascer, e não na morte, como promovem muitas religiões. 
Os exemplos que trouxemos à nossa escrita apontam para um leitor capaz de fazer relações e, no caso da ironia, olhar a linguagem pelo avesso, na tentativa de encontrar-lhe o significado. É o tipo de leitor que Duarte (2006, p. 19) assinala em sua obra como participativo no processo de percepção de tal recurso de construção literária:

A ironia, afirmação de um indivíduo que reconhece a natureza intersubjetiva de sua individualidade, serve dessa forma à literatura, quando esta busca um leitor que não seja passivo, mas atento e participante, capaz de perceber que a linguagem não tem significados fixos e que o texto lhe pode apresentar armadilhas e jogos de enganos, dos quais deverá, eventualmente, participar.

O leitor, no caso da edição de Se os tubarões fossem homens, é convidado a ter uma experiência proveitosa também na fruição das ilustrações e no entendimento das relações que elas estabelecem com o texto verbal. Projetos ilustrativos arrojados e ousados como o de Nelson Cruz para o livro em questão tornam-se aliados da criança leitora à medida que se colocam a par de sua capacidade de pensar e criar relações (e, portanto, transitar) tanto por um caminho (a palavra que influencia a compreensão da ilustração), quanto pelo outro (a ilustração que influencia a compreensão do texto verbal). Esses movimentos levam a criança a perceber e se relacionar com a linguagem verbal e visual, separada ou simultaneamente:

Os livros-ilustrados podem desenvolver a diferença entre ler palavras e ler imagens: não são limitados por sequência linear, mas podem orquestrar o movimento dos olhos. O mais importante, como disse Sônia Landes, é que "no entendimento dos ilustradores de hoje, os livros-ilustrados lidam na realidade com os dois argumentos, o visual e o verbal; e cada um pode ser escalonado separadamente para um mútuo reforço, contraponto, antecipação ou expansão". (HUNT, 2010, p. 234).

A possibilidade de orquestrar o movimento dos olhos nada mais é que o leitor orientar-se pelo livro ilustrado tendo como guia o texto verbal e a ilustração simultaneamente, levando ao entrelaçamento de ambos, o que confere a não linearidade à obra, conforme as palavras de Hunt. A possibilidade de lê-los em separado aponta, no texto, para os dois argumentos a que se referiu Sônia Landes: o verbal e o visual. "Eles 
[os dois argumentos ou os dois contingentes de significados] têm um grande potencial semiótico/semântico, decididamente não são simples coleções de imagens [...]" (HUNT, 2010, p. 234). As ilustrações de Nelson Cruz para o texto de Brecht servem para demonstrar as possibilidades que comentamos a partir do fragmento de Hunt. Longe de funcionar como simples reprodução visual daquilo que já foi informado pelo texto verbal, as ilustrações propõem ao leitor, a cada página, um contingente de informações que, em muitas ocasiões, não estão no texto, e que, por vezes, choca-se com as afirmações do senhor K., na narrativa. Um exemplo dessa multiplicidade de informações é a ilustração da FIGURA 1.

FIGURA 1 - Multiplicidade de informações na ilustração para página dupla de Se os tubarões fossem homens

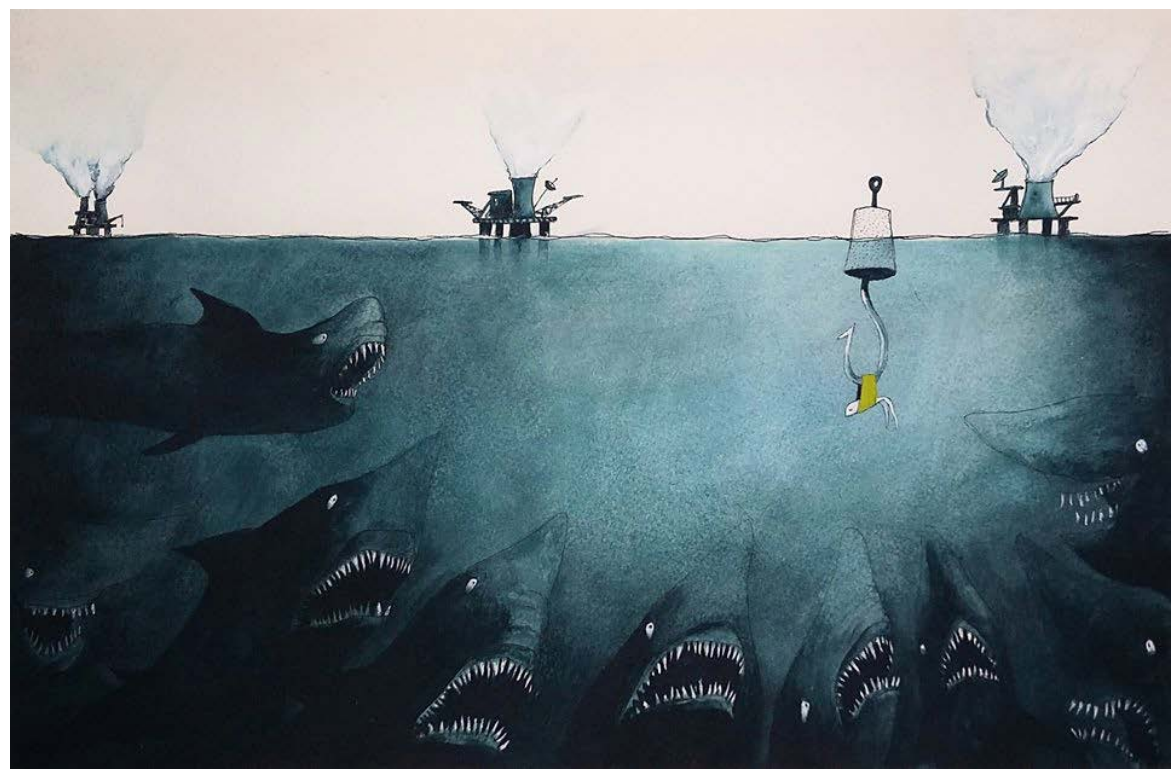

Fonte: Arquivo pessoal de Nelson Cruz

O texto que foi inserido na página dupla é o seguinte: "Se, por exemplo, um peixinho machucasse a nadadeira, os tubarões logo mandariam fazer um curativo para que ele não morresse antes do tempo" (BRECHT, 2018). Mas o que a criança percebe é um peixinho doente usado como isca junto aos tubarões famintos. Esse tipo de relação entre texto e imagem expõe o leitor ao que há de amistoso e provocativo nos 
livros para a infância. É a mudança de rota, tendo em vista o texto verbal, que torna rica a experiência da leitura, a qual, em projetos arrojados, não é segura nem linear, lembrando uma afirmação da pesquisadora Marta Morais da Costa (2006, p. 159): “Toda construção de sentidos é arriscada. A atividade leitora consiste num salto sem para quedas e sem solo onde aterrar. A única certeza é a do voo e a do mapa desenhado pelo texto".

Além disso, o trabalho de Nelson Cruz em torno das ilustrações de Se os tubarões fossem homens nos faz pensar o livro ilustrado na confluência das diversas imagens e do texto escrito, como bem assinalou Hunt:

Esse é um meio no qual as páginas podem ser vistas em termos de aberturas e de livre exploração das interações entre os dois meios [visual e verbal], pois como disse Nicholas Tucker, "a arte do livro ilustrado [...] reside nas interações entre a ilustração e o texto". (HUNT, 2010, p. 234-236).

Para que o leitor possa investigar esse tipo de ilustração - que os autores assinalam como mais apropriada para o livro ilustrado -, os projetos ilustrativos precisam proceder de modo a colocar texto e ilustração em conexão criativa, de modo a conceber a ilustração como reveladora de potencialidades que o texto guarda, em um movimento que complexifica palavra e ilustração, e não na simples tradução da primeira para a segunda. Maria Nikolajeva e Carole Scott são pontuais quanto ao envolvimento das palavras e das imagens no livro ilustrado, ao afirmarem que, nesse produto cultural, as palavras e as imagens trabalham juntas para criar o impacto do livro.

Os exemplos mais eficazes criam alguma tensão entre as informações trazidas pelas palavras e pelas ilustrações, de modo a colaborar mutuamente, em vez de apenas repetir de forma redundante o que é comunicado no outro modo de expressão. (NIKOLAJEVA; SCOTT, 2011, p. 327).

Projetos como o de Nelson Cruz só se concretizam porque o artista explora com liberdade a interação entre a imagem e a palavra, como prevê Hunt. Se estivesse preso à ideia de traduzir uma linguagem na outra, seu trabalho não resultaria criativo e ousado. A realização visual do artista, aliás, é exemplar em criar tensões em relação ao texto escrito. Quanto à utilização da expressão "criar tensões", neste campo 
de estudos, ela não tem uma conotação negativa e tampouco significa um resultado desfavorável à criatividade. Ela supõe criar condições para que a ilustração jogue de modo inventivo, provocativo e até subversivo com o texto. Nesse sentido, cabem duas exemplificações a partir da obra em análise. Nas ilustrações de Nelson Cruz, há um peixinho vermelho, inconformado e contestador que aparece em quase todas as páginas duplas. Se não pela cor, ele se destaca por estar sempre nadando em direção contrária à maioria dos outros peixes e levando alguns outros peixes consigo. Na FIGURA 2, é possível observar a personagem.

FIGURA 2 - A personagem na ilustração para página dupla de Se os tubarões fossem homens

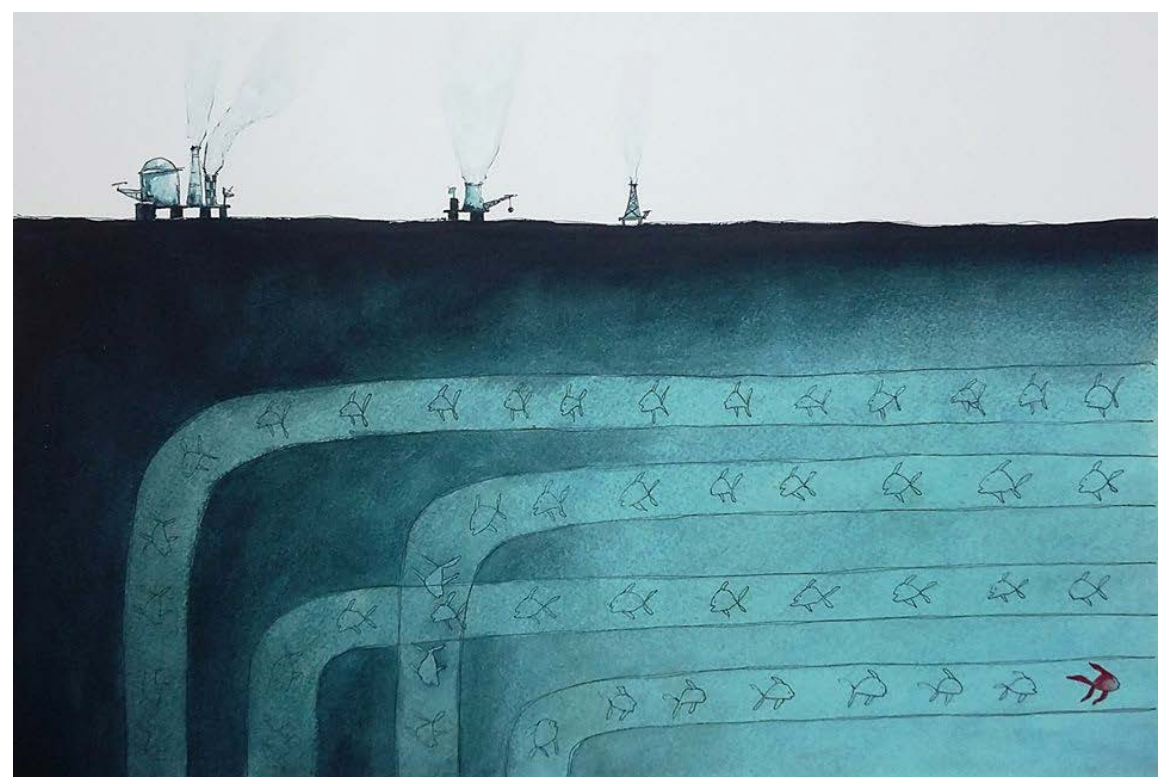

Fonte: Arquivo pessoal de Nelson Cruz

Em momento algum do texto, Brecht menciona o peixinho vermelho. Trata-se de uma elaboração do ilustrador, um caso bem pontual de criação de tensão nos moldes de que tratávamos. Vermelho também é o casaco da menina interlocutora do senhor K., desenhada na capa e na primeira página dupla de ilustrações. $\mathrm{Na}$ interpretação do ilustrador - e nós concordamos com ela - a literatura de Brecht favorece o despertar crítico e a consciência política, e a criança que entrar em contato com a 
sua produção literária desde cedo tem condições de perceber o mundo por um viés questionador e desacomodado.

Outro momento em que percebemos o estabelecimento da tensão referida por Nikolajeva e Scott na obra em evidência é no encerramento do texto. A última afirmativa do senhor K. é a seguinte: "Em resumo, só existiria uma civilização no mar se os tubarões fossem homens" (BRECHT, 2018). O conteúdo da afirmativa é contrariado por uma ilustração em página dupla que apresenta as gaiolas quebradas, os peixes coloridos e de vários formatos fugindo, em uma provocação à ideia de civilização única. Na dupla em questão, a página da esquerda reproduz o fundo do mar com azul esverdeado, a da direita é branca, em claro estímulo à capacidade de imaginação da criança: afinal, que final é esse? Os peixes saíram do mar? Que lugar ocupam no final da história? Proposta bastante similar repete-se na última página.

Se os tubarões fossem homens, embora escrito na primeira metade do século passado, dialoga com o Brasil contemporâneo ao refletir sobre a organização social do mundo e suas implicações de várias ordens. É um texto indicado, no catálogo das edições Olho de Vidro, para os leitores a partir de dez anos, idade que corresponde ao leitor fluente, tendo em vista as categorias apresentadas por Nelly Novaes Coelho (2000). Essa é a "[...] fase de consolidação do domínio do mecanismo da leitura e da compreensão do mundo expresso no livro" (COELHO, 2000, p. 37). Também é a fase, segundo a autora, do alargamento ou aprofundamento da percepção do mundo pela criança. Os leitores brasileiros que entrarem em contato com a obra terão oportunidade de realizar uma reflexão sobre o mundo e o país em que vivem a partir do conteúdo e da linguagem apresentados por Brecht, bem como pelas ilustrações de Nelson Cruz. A obra não está a exigir demais do leitor em questão que, segundo Coelho, já consegue fazer relações entre aquilo que lê e as características do mundo que o cerca e, agora de acordo com nossa percepção, não é indiferente às injustiças e descalabros que podem vir a caracterizar o sistema político e social. 
Eixo Roda, Belo Horizonte, v. 28, n. 3, p. 281-289, 2019

\section{Referências}

BRECHT, Bertolt. Se os tubarões fossem homens. Tradução de Cristiane Röhrig. Ilustrações de Nelson Cruz. Curitiba: Edições Olho de Vidro, 2018.

COELHO, Nelly Novaes. Literatura infantil: teoria, análise, didática. São Paulo: Moderna, 2000.

COSTA. Marta Morais. Mapa do mundo: crônicas sobre leitura. Belo Horizonte: Leitura, 2006.

DUARTE, Lélia Parreira. Ironia e humor na literatura. Belo Horizonte: PUC Minas, 2006.

HUNT, Peter. Crítica, teoria e literatura infantil. Tradução de Cid Knipel. São Paulo: Cosac Naify, 2010.

NIKOLAJEVA, Maria; SCOTT, Carole. Livro ilustrado: palavras e imagens. Tradução de Cid Knipel. São Paulo. Cosac Naify, 2011.

Recebido em: 27 de fevereiro de 2019.

Aprovado em: 20 de maio de 2019. 